\title{
Một số bất cập về pháp luật giao dịch bằng hợp đồng điện tử tại Việt Nam
}

\section{Some gaps and inadequacies in Vietnam's law on e-transactions}

\author{
Lê Hữu Nghĩa ${ }^{1 *}$ \\ ${ }^{1}$ Khoa Luật, Trường Đại học Kinh tế Thành phố Hồ Chí Minh, Việt Nam \\ "Tác giả liên hệ, Email: nghia.huule@ yahoo.com
}

THÔNG TIN

DOI: $10.46223 / \mathrm{HCMCOUJS}$. soci.vi.16.2.1924.2021

Ngày nhận: 10/06/2021

Ngày nhận lại: 29/07/2021

Duyệt đăng: 07/08/2021

Tù khóa:

chữ ký điện tử; công chứng hợp đồng điện tử; hợp đồng điện tử; thông điệp dữ liệu

Keywords:

eletronic signature; notarization of e-contracts; e-contract; data message

\section{TÓM TÁT}

Cuộc cách mạng công nghiệp lần thứ tư đang diễn ra sôi nổi trên phạm vi toàn cầu cùng với sự phát triển vượt bậc và không ngừng của khoa học kỹ thuật được ứng dụng trong mọi mặt đời sống, kinh tế, pháp luật. Tuy nhiên, pháp luật điều chỉnh về giao dịch bằng hợp đồng điện tử vẫn còn một số bất cập có thể dẫn đến rủi ro cho các chủ thể tham gia giao kết hợp đồng như: khó khăn và tốn nhiều chi phí trong việc thu thập và kiểm tra tính xác thực của chứng cứ từ thông điệp dữ liệu; thiếu quy định cụ thể về hình thức chữ ký scan và chữ ký hình ảnh; chưa có quy định về công chứng hợp đồng điện tử. Những bất cập này lần lượt được chỉ ra qua các phương pháp tra cứu, so sánh và phân tích luật viết nhằm đưa ra các gợi ý điều chỉnh và cải thiện hiệu quả và khả thi tương ứng với từng vấn đề pháp lý hiện còn tồn tại.

ABSTRACT
The Fourth Industrial Revolution is actively taking place on a
global scale by the considerable development and ever-changing
evolution in science and technology applied in all aspects of life,
the economy, and law. However, the rules which are regulating
the transactions of electronic contracts (e-contracts) still have
some inadequacies that can lead to risks for the parties
participating in a contract, such as difficulties and costly
collection to verify the authenticity of evidence of data messages;
lack of specific regulations on the form of scanned signatures and
pictured signatures; there are no regulations on notarization of e-
contracts. These gaps and inadequacies are in turn pointed out
through the methods of searching, comparing, and analyzing the
statutory law in order to give suggestions for adjustment and
improvement of efficiency and feasibility corresponding to each
existing legal issue.

\section{Giới thiệu}

Tình hình đại dịch Covid-19 đang bùng nổ trên thế giới với tính chất nguy hiểm và lây lan nhanh chóng, phức tạp trong công tác kiểm soát, phòng chống. Do đó, xu thế giao dịch trực tuyến đang được nhấn mạnh và ưu tiên vận hành. Tuy nhiên, pháp luật điều chỉnh về giao dịch 
bằng hợp đồng điện tử vẫn còn một số bất cập có thể dẫn đến rủi ro cho các chủ thể tham gia giao kết hợp đồng như: khó khăn và tốn nhiều chi phí trong việc thu thập và kiểm tra tính xác thực của chứng cứ từ thông điệp dữ liệu; thiếu quy định cụ thể về hình thức chữ ký scan và chữ ký hình ảnh; chưa có quy định về công chứng Hợp đồng điện tử. Bên cạnh đó, cuộc cách mạng công nghiệp lần thứ tư đang diễn ra sôi nổi trên phạm vi toàn cầu cùng với sự phát triển vượt bậc và không ngừng của khoa học kỹ thuật được ứng dụng trong mọi mặt đời sống, kinh tế, pháp luật. Vì thế, việc nghiên cứu và tìm ra những bất cập về pháp luật giao dịch bằng hợp đồng điện tử tại Việt Nam là một trong những đòi hỏi cấp thiết nhằm góp ý cho các cơ quan có thẩm quyền về lập pháp kịp thời nhận dạng và có hướng điều chỉnh phù hợp với tình hình mới.

\section{Cơ sở lý thuyết}

\subsection{Hợp đồng và lý thuyết về Luật hợp đồng}

\subsection{1. Định nghĩa về hợp đồng}

Theo từ điển chuyên về Luật Oxford do Martin (2002, p. 114) hiệu đính, thuật ngữ "hợp đồng" được giải thích là "Một thỏa thuận ràng buộc pháp lý. Thỏa thuận phát sinh do kết quả của sự đề nghị và chấp nhận, đồng thời, một số yêu cầu khác phải được đáp ứng để thỏa thuận có giá trị ràng buộc về mặt pháp lý." Các yếu tố khác bao gồm: (i) tính đối ứng về quyền và nghĩa vụ; (ii) ý định tạo lập quan hệ pháp luật giữa các bên; (iii) năng lực giao kết hợp đồng giữa các bên; (iv) thỏa thuận phải tuân thủ mọi yêu cầu về hình thức theo quy định của pháp luật; (v) thỏa thuận phải hợp pháp; (vi) thỏa thuận không bị vô hiệu toàn phần bởi một số các quy định pháp luật có khiếm khuyết và hoặc một số hợp đồng nhất định, mặc dù có hiệu lực nhưng có thể bị một trong các bên hủy bỏ hợp đồng với lý do nhầm lẫn hoặc bị gây ảnh hưởng quá mức (the exercise of undue influence).

Tuy nhiên theo từ điển pháp luật khá nổi tiếng của Mỹ - "Deluxe Black's Law Dictionary" do Garner (2009) hiệu đính chính, tái bản lần thứ 09, đưa ra hai định nghĩa về hợp đồng. Định nghĩa đầu tiên cho rằng hợp đồng là sự thỏa thuận từ hai hoặc nhiều người trở lên tạo thành thứ gọi là nghĩa vụ cần phải làm hoặc không làm đối với vấn đề cụ thể nào đó. Định nghĩa thứ hai nghiêng về trách nhiệm của sự hứa hẹn. Cụ thể, định nghĩa này giải thích hợp đồng là một hoặc một số lời hứa hẹn mà nếu chủ thể đưa ra không thực hiện được coi là vi phạm thỏa thuận và pháp luật sẽ có quy định chế tài về sự vi phạm ấy. Lời hứa hẹn được xem như một trách nhiệm.

Theo Ngo (2013), định nghĩa về hợp đồng tựu trung bao gồm hai nội dung chính: (i) thống nhất ý chí bằng việc trao đồi, thỏa thuận; (ii) tạo lập ra hậu quả pháp lý. Trước đó, theo Vu (1963, p. 83), "sụ kết lập khế ước cần có ba điều kiện là sụ ung thuận của người kết uớc đại diện của họ; một chủ đích xác định; một nguyên nhân đích thực và hợp lý."

\subsubsection{Lý thuyết về luật hợp đồng}

Cũng theo Vu (1963, p. 53), thời cổ đại Gaius, người ta đã hình thành nên thuyết các quy tắc về hợp đồng nhu "phàm nghĩa vu đều do các khế vớc hay các dân sự phạm phát sinh ra" và theo Ngo (2013) thì người La Mã cổ đại đã phân chia nghĩa vụ thành ba loại: nghĩa vụ tự nhiên, nghĩa vụ dân sự, nghĩa vụ đạo đức.

Theo O’Sullivan và Hilliard (2012), hệ thống Thông luật không giống như Luật La Mã, không có luật hợp đồng mang tính hệ thống và riêng biệt. Bởi vì các luật sư không phân tích các tranh chấp dưới giác độ các quy tắc thực định, mà bằng cách tham khảo câu hỏi mang tính thủ tục về "hình thức của hành vi" nào được áp dụng. Mãi đến thế kỷ XIX, quyển sách giáo khoa đầu tiên về Luật Hợp đồng mới được viết, nó phản ánh một sự thật rằng lần đầu tiên có một triết lý thống nhất về hợp đồng và tranh chấp hợp đồng đã xuất hiện và được chấp nhận. Triết lý này 
thường được gọi là lý thuyết hợp đồng cổ điển và nó vẫn còn có những ảnh hưởng cực kỳ lớn cho đến ngày nay. Ngoài ra lý thuyết hợp đồng cổ điển đưa ra những biện minh đầy thuyết phục cho phần lớn luật hợp đồng đương đại.

Lý thuyết hợp đồng cổ điển có ba chủ đề liên quan. Thứ nhất, hợp đồng là một giao kèo hay một thỏa thuận có đi có lại giữa các bên, gần như luôn luôn là sự trao đổi những lời hứa. Do đó, một lời hứa vô cớ từ một phía không phải là một hợp đồng. Thứ hai, hợp đồng là sản phẩm ý chí của các bên, do đó ý định tự "ràng buộc" của các bên nhằm biện minh cho sự thừa nhận hợp pháp về các quyền và nghĩa vụ hợp đồng đối với việc thực thi. Thứ ba, tự do giao kết hợp đồng là điều tối quan trọng. Mọi người được tự do quyết định xem có ký hợp đồng hay không, họ sẵn sàng ký hợp đồng với ai và theo những điều khoản nào. Luật phải can thiệp ít nhất có thể và chỉ đảm bảo rằng các chiến lược không hợp pháp từ một bên, chẳng hạn như gian lận hoặc ép buộc sẽ bị kiểm soát quản lý nhằm kiểm soát và đảm bảo không phương hại đến quyền tự do đàm phán của bên kia.

Theo Reed, Cheeseman, và Schlageter III (2013), lý thuyết về luật hợp đồng hiện đại cho rằng các bên có thể tự do thương lượng các điều khoản hợp đồng nhưng phải tuân thủ các quy định của cơ quan ban hành và quản lý về pháp luật có liên quan.

\subsection{Hợp đồng truyền thống, hợp đồng điện tử, chũ ký điện tử}

Có thể nhận diện các đặc điểm của Hợp Đồng Truyền Thống (HĐTT), Hợp Đồng Điện Tử (HĐĐT) và Chữ Ký Điện Tử (CKĐT) theo Reed và cộng sự (2013) như sau:

\section{Bảng 1}

Hợp đồng truyền thống, hợp đồng điện tử và chữ ký điện tử

\begin{tabular}{|c|c|c|}
\hline Hợp đồng truyền thống & Hợp đồng điện tử & Chữ ký điện tử \\
\hline $\begin{array}{l}\text { Là một tài liệu thường } \\
\text { được in sẵn, cần được điền } \\
\text { thông tin vào và được áp } \\
\text { dụng cho nhu cầu của một } \\
\text { khách hàng cụ thể }\end{array}$ & $\begin{array}{l}\text { Hợp đồng điện tử là loại hợp } \\
\text { đồng phát sinh trong thương } \\
\text { mại điện tử, được hình thành } \\
\text { dưới dạng điện tử qua Internet } \\
\text { bằng e-mail và hệ thống } \\
\text { World Wide Web }\end{array}$ & $\begin{array}{l}\text { Chữ ký điện tử hay còn gọi là } \\
\text { chữ ký số là chữ ký phải đáp } \\
\text { ứng các yêu cầu sau: (i) yêu } \\
\text { cầu về các tiêu chuấn phòng } \\
\text { chống gian lận; (ii) tính đồng } \\
\text { nhất, xác thực và cam kết có } \\
\text { hiệu lực như chữ ký trên giấy }\end{array}$ \\
\hline
\end{tabular}

Nguồn: Tác giả tự tóm tắt theo Reed và cộng sự (2013)

\section{Phương pháp nghiên cứu}

\subsection{Câu hỏi nghiên cứu}

Câu hỏi 1: Các quy định về pháp luật hợp đồng và hợp đồng điện tử cùng thực trạng pháp luật điều chỉnh tại Việt Nam liên quan đến giao dịch bằng hợp đồng điện tử như thế nào?

Câu hỏi 2: Bất cập của các quy định pháp luật điều chỉnh về giao dịch bằng hợp đồng điện tử là gì và những bất cập này có thể dẫn đến rủi ro như thế nào cho các chủ thể tham gia giao kết?

Câu hỏi 3: Các đề xuất, gợi ý nhằm cải thiện các bất cập?

\subsection{Phương pháp nghiên cứu}

Phương pháp tra cứu, so sánh được sử dụng để tìm kiếm, đối chiếu và tổng hợp các tài liệu từ các nguồn thông tin đáng tin cậy như các bài báo khoa học trên google scholar, các tạp chí nghiên cứu trực tuyến, sách, báo, văn bản công khai, minh bạch có liên quan, ... nhằm giải quyết câu hỏi nghiên cứu 1 ; 
Phương pháp phân tích luật viết bao gồm phương thức phân tích quy nạp và phân tích diễn dịch để làm rõ vấn đề đối với câu hỏi nghiên cứu 2 và 3 .

\section{Kết quả nghiên cứu và thảo luận}

\subsection{Thục trạng pháp luật điều chỉnh về giao dịch bằng hợp đồng điện tử tại Việt Nam}

\subsubsection{Giao dịch Hợp đồng điện tư}

Bộ Luật Dân sự năm 2015 (BLDS 2015) đưa ra khái niệm về hợp đồng như sau: "Hợp đồng là sự thỏa thuận giữa các bên về việc xác lập, thay đổi hoặc chấm dứt quyền, nghĩa vu dân sự" (Điều 385, Quốc hội, 2015a). Theo đó, BLDS 2015 điều chỉnh về giao dịch dân sự thông qua phương tiện điện tử dưới hình thức thông điệp dữ liệu sẽ theo quy định của pháp luật về giao dịch điện tử và điều này được xem là giao dịch bằng văn bản (Khoản 1 , Điều 119). Từ đây, khi xem xét Luật Giao dịch điện tử năm 2005 (Luật GDĐT 2005), ta thấy Luật này định nghĩa: "Hợp đồng điện tư là hợp đồng được thiết lập duới dạng thông điệp dũ liệu theo quy định của Luật này” (Điều 33, Luật GDĐT 2005, Quốc hội, 2005).

Thuật ngữ "giao kết hơpp đồng điện tư" theo quy định của Luật GDĐT 2005 là "việc sư dụng thông điệp dư liệu để tiến hành một phần hoạc toàn bộ giao dịch trong quá trình giao kết hơp đồng" (Khoản 1, Điều 36, Luật GDĐT 2005, Quốc hội, 2005). Trong đó, Luật GDĐT 2005 giải thích "thông điệp dũ liệu là thông tin được tạo ra, được gửi đi, được nhận và được luu trũ bằng phuoong tiện điện tü" (Khoản 12, Điều 4, Luật GDĐT 2005, Quốc hội, 2005).

Như vậy, từ những quy định trên, ta có thể rút ra một số đặc điểm đặc trưng của HĐĐT như sau:

Thư nhất, về giá trị pháp lý, HĐĐT có giá trị pháp lý như các hợp đồng truyền thống khác nhưng nó được tạo ra hay thiết lập, lưu trữ trong không gian mạng và dữ liệu thông tin theo ý chí của con người được mã hóa. Thêm vào đó, chúng ta không thể cầm, nắm, hoặc tác động vật lý tương tự như đối với HĐTT khác (bằng văn bản).

Thư hai, về giao kết, HĐĐT được thực hiện thông qua phương tiện điện tử. Nội dung về các điều khoản hợp đồng được chuyển tải bằng thông điệp điện tử. Trong đó chữ ký trong hợp đồng có thể được số hóa.

Thư $b a$, về chủ thể tham gia giao kết, HĐĐT luôn xuất hiện chủ thể là nhà cung cấp mạng viễn thông và dịch vụ chữ ký số. Chủ thể này vừa có vai trò tham gia vào giao dịch điện tử bằng việc hỗ trợ truyền tải dữ liệu, vừa có vai trò xác nhận, lưu trữ thông tin với độ tin cậy nhất định.

Thư $t u$, về phạm vi ký kết, HĐĐT có thể được ký kết mọi lúc mọi nơi theo ý chí của các bên nếu đảm bảo về các điều kiện về vận hành, kết nối mạng.

Như vậy từ những đặc điểm trên mà HĐĐT có những ưu điểm vượt trội và được sử dụng trong giao dịch thương mại ngày càng phổ biến, nhất là trong xu thế phát triển của cuộc $\mathrm{CMCN}$ 4.0 và sự bùng phát của dịch bệnh Covid-19.

\subsubsection{Giá trị pháp lý của chưng cứ thông điệp dũ liệu và chũ ký điện tử}

- Giá trị pháp lý của chứng cứ thông điệp dữ liệu

Bộ luật Tố tụng dân sự năm 2015 (BL TTDS 2015) xác định: "Chứng cú trong vu việc dân sự là nhũng gì có thật được đương sụ và co quan, tổ chức, cá nhân khác giao nộp, xuất trình cho Tòa án trong quá trình tố tụng hoạc do Tòa án thu thập được theo trình tụ, thủ tục do Bộ luật này quy định và được Tòa án sủ dụng làm căn cứ để xác định các tình tiết khách quan của vu án cũng như xác định yêu cầu hay sụ phản đối của đương sụ là có căn cứ và hợp pháp" (Điều 93, BL TTDS 2015, Quốc hội, 2015b). Ngoài ra, BL TTDS 2015 cũng quy định về thông điệp 
dữ liệu điện tử được xác định dưới các hình thức như "trao đổi dũ liệu điện tư;; thu điện tư; điện tín; điện báo; fax; các hình thức tuoong tụ khác theo quy định của pháp luật về giao dịch điện tử" (Điều 95, BL TTDS 2015, Quốc hội, 2015b).

Theo Luật GDĐT 2005 thì "thông điệp dũ liệu không bị phủ nhận giá trị dùng làm chưng cứ nếu chỉ vì đó là một thông điệp dũ liệ" (Khoản 1, Điều 14, Luật GDĐT 2005, Quốc hội, 2005). Giá trị pháp lý của HĐĐT liên quan đến thông điệp dữ liệu cũng được Luật này thừa nhận: "Giá trị pháp lý của hợp đồng điện tư không thể bị phủ nhận chỉ vì hợp đồng đó được thể hiện dưới dạng thông điệp dư liệu" (Điều 34, Luật GDĐT 2005, Quốc hội, 2005).

Xét về giá trị chứng cứ, thông điệp điện tử có những căn cứ xác định như là "độ tin cậy cách khởi tạo, luu trũ hoặc truyền gưi thông điệp dĩu liệu; cách thức bảo đảm và duy trì tính toàn vẹn của thông điệp dĩ liệu; cách thức xác định người khởi tạo và các yếu tố phù hợp khác" (Khoản 2, Điều 14, Luật GDĐT 2005, Quốc hội, 2005).

Như vậy, từ các cơ sở dẫn chiếu trên, ta thấy HĐĐT có cơ sở pháp lý và giá trị chứng cứ trong giao dịch điện tử cũng như trong tranh chấp nếu phát sinh.

- Chữ ký điện tử

Thông thường, đối với giao dịch bằng HĐĐT, khi ký kết, theo Truong và Huynh (2020) các bên có 03 phương thức sử dụng chữ ký phổ biến sau:

\section{Bảng 2}

Mô tả về chữ ký điện tử

\begin{tabular}{|c|c|c|c|}
\hline & Chữ ký số & Chứ ký scan & $\begin{array}{c}\text { Chữ ký bằng } \\
\text { hình ảnh }\end{array}$ \\
\hline Mô tả & $\begin{array}{l}\text { - Chữ ký số được tạo } \\
\text { ra từ một bên cấp } \\
\text { dịch vụ chứng thực } \\
\text { chữ ký số cho các } \\
\text { bên có nhu cầu trên } \\
\text { một nền tảng công } \\
\text { nghệ tin học và thiết } \\
\text { bị chuyên dụng. } \\
\text { - Sau đó chữ ký số } \\
\text { được chèn vào hợp } \\
\text { đồng cần ký kết dưới } \\
\text { dạng điện tử }\end{array}$ & $\begin{array}{l}\text { - Chữ ký scan được } \\
\text { tạo ra bằng cách mỗi } \\
\text { bên tham gia kí kết } \\
\text { hợp đồng ký trực tiếp } \\
\text { vào nội dung của văn } \\
\text { bản hợp đồng. } \\
\text { - Sau đó hợp đồng vừa } \\
\text { được ký trực tiếp đó } \\
\text { sẽ được quét } \\
\text { (scanning) chuyển } \\
\text { thành dạng điện tử và } \\
\text { được gửi đi bằng thư } \\
\text { điện tử }\end{array}$ & $\begin{array}{l}\text { - Chữ ký bằng hình } \\
\text { ảnh được tạo ra bằng } \\
\text { cách các bên tham gia } \\
\text { ký kết hợp đồng chèn } \\
\text { hình ảnh chữ ký của } \\
\text { mình vào hợp đồng. } \\
\text { - Sau đó hợp đồng này } \\
\text { được lưu dưới dạng } \\
\text { tập tin dữ liệu (pdf, } \\
\text { doc, ...) và tập tin này } \\
\text { được gửi đi bằng thư } \\
\text { điện tử }\end{array}$ \\
\hline Úng dụng & $\begin{array}{l}\text { Phương thức này } \\
\text { thường được ứng } \\
\text { dụng đối với giao } \\
\text { dịch có trị giá nhỏ } \\
\text { như nộp tờ khai hải } \\
\text { quan, nộp thuế } \\
\text { online, phát hành hóa } \\
\text { đơn điện tử... }\end{array}$ & $\begin{array}{l}\text { Phương thức này được } \\
\text { ứng dụng khi có nhiều } \\
\text { bên tham gia hợp } \\
\text { đồng và có sự cách trở } \\
\text { về địa lý lẫn không có } \\
\text { mặt cùng một thời } \\
\text { điềm. Do đó, các hợp } \\
\text { đồng có các chủ thể ở } \\
\text { các quốc gia khác } \\
\text { nhau thường ứng dụng } \\
\text { chữ ký scan }\end{array}$ & $\begin{array}{l}\text { Phương thức này } \\
\text { thường được ứng } \\
\text { dụng đối với giao dịch } \\
\text { có trị giá nhỏ, không } \\
\text { phải ký nhiề lần, } \\
\text { những người tham gia } \\
\text { ký kêt không có mặt ở } \\
\text { cùng một địa điểm }\end{array}$ \\
\hline
\end{tabular}

Nguồn: Tác giả tự tóm tắt theo Truong và Huynh (2020) 
Chữ ký scan là phương thức được áp dụng phổ biến đối với giao dịch hợp đồng có giá trị lớn và phức tạp. Trong khi, chữ ký số thường sẽ chiếm ưu thế sử dụng đối với các hợp đồng có tính chất tiêu dùng.

Về mức phổ biến, theo thứ tự giảm dần ta có thể xếp các phương thức này như sau: chữ ký scan, chữ ký hình ảnh, chữ ký số Truong và Huỳnh (2020).

Về khung pháp lý đối với CKĐT, Luật GDĐT 2005 đưa ra các đặc tính của CKĐT như "được tạo lập dưới dạng tì̀, chũu, số, ký hiệu, âm thanh hoạc các hình thức khác bằng phuơng tiện điện tữ; gắn liền hoặc kết hợp một cách lô gíc với thông điệp dư liệ; có khả năng xác nhận ngườ ký thông điệp dũ liệu và xác nhận sự chấp thuận của ngườ đó đối với nội dung thông điệp dũ liệu được ky" (Khoản 1, Điều 21, Luật GDĐT 2005, Quốc hội, 2005).

Về giá trị pháp lý, CKĐT phải đáp ứng các điều kiện như "phuơng pháp tạo chũ ký điện tư cho phép xác minh được ngườ ký và chứng tỏ được sự chấp thuận của người ký đối với nọi dung thông điệp dũ liệ; phưong pháp đó là đủ tin cậy và phù hợp với muc đích mà theo đó thông điệp dũ liệu được tạo ra và gưi đi" (Khoản 2, Điều 24, Luật GDĐT 2005, Quốc hội, 2005).

Hiện tại, theo Pháp luật hiện hành chỉ có chữ ký số được quy định rõ là một loại CKĐT (Nghị định 130/2018/NĐ-CP, Chính phủ, 2018 và Nghị định 52/2013/NĐ-CP, Chính phủ, 2013), chữ ký scan và chữ ký bằng hình ảnh chưa có quy định pháp luật điều chỉnh. Một số quy định điều chỉnh đến chữ ký số như "văn bản được ký bằng chũ ký số không nhất thiết bắt buộc phải đóng dấu" (Khoản 2, Điều 8, Nghị định 130/2018/NĐ-CP, Chính phủ, 2018); “chũ ký số có giá trị pháp lý và được công nhận trong việc gửi các tài liệu cho Tòa án mà không làm phát sinh các vấn đề về tính hiệu lưc" (Khoản 1, Điều 7, Nghị quyết số 04/2016/NQ-HĐTP ngày 30/12/2016, Chính phủ, 2016a); “chũ ký số và chưng thu số nước ngoài được cấp giấy phép sử dụng tại Việt Nam có giá trị pháp lý và hiệu lực như chũ ký số và chứng thư số do tổ chức cung cấp dịch vư chứng thực chữ ký số công cộng của Việt Nam cấp" (Khoản 3, Điều 8, Nghị định 130/2018/NĐCP, Chính phủ, 2018); "tổ chức cung cấp dịch vụ chứng thục chũ ký số chuyên dùng của các co" quan, tổ chức được cấp giấy chứng nhận đủ điều kiện đảm bảo an toàn cho chũ ký số chuyên dùng đuợc quy định theo Pháp luật Việt Nam" (Điểm d, Khoản 2, Điều 9, Nghị định 130/2018/NĐ-CP, Chính phủ, 2018).

- Hoạt động công chứng HĐĐT

Hiện nay, Luật công chứng năm 2014, sửa đổi năm 2018 vẫn chưa có quy định điều chỉnh về việc công chứng hợp đồng, giao dịch điện tử (Quốc hội, 2014).

Tuy nhiên tại Nghị định 52/2013/NĐ-CP ngày 16/05/2013 (Chính phủ, 2013) quy định về thương mại điện tử có điều chỉnh chung về hoạt động chứng thực HĐĐT như "Điều kiện cấp phép hoạt động cho thương nhân, tổ chức cung cấp dịch vu chứng thực hợp đồng điện tư; Giấy phép hoạt động của thwơng nhân, tổ chức cung cấp dịch vu chứng thực hợp đồng điện tư có thời hạn theo đề nghị cấp phép; Nghĩa vu của thuơng nhân, tổ chức cung cấp dịch vu chứng thưc hơp đồng điện tư; Trách nhiệm của Bộ Công Thuơng là quy định chi tiết về thủ tục thành lập và quy chế hoạt động của thuơng nhân, tổ chức cung cấp dịch vu chứng thực hợp đồng điện tứ; các truờng hợp thu hồi giấy phép hoạt động; trình tụ, thủ tục cấp, sửa đổi bổ sung, thu hồi giấy phép hoạt động của các thương nhân, tổ chức này" (Điều 63, Nghị định 52/2013/NĐ-CP, Chính phủ, 2013).

\subsection{Thảo luận về bất cập pháp luật điều chỉnh về giao dịch bằng hợp đồng điện tủ̉}

Mặc dù, khung pháp lý về giao dịch bằng hợp đồng điện tử được điều chỉnh từ Luật chung mang tính nền tảng là BLDS cho đến luật chuyên ngành là Luật GDĐT và một số các văn bản pháp luật khác. Tuy nhiên, đối với giao dịch dân sự này ở Việt Nam, ta thấy vẫn còn tồn tại 
một số bất cập hiện hữu cần quan tâm nghiên cứu và điều chỉnh cho phù hợp với tình hình thực tế nhằm hạn chế các rủi ro về tính hiệu lực pháp luật của hợp đồng xét về giác độ hình thức, chi phí trong việc thu thập, kiểm tra tính xác thực của chứng cứ khi xảy ra tranh chấp, cũng như việc thúc đẩy áp dụng thành tựu công nghệ mới trong lĩnh vực pháp luật.

\subsubsection{Khó khăn và tốn nhiều chi phí trong việc thu thập, kiểm tra tính xác thực của} chứng cứ tù̀ thông điệp dũ liệu

Trong vận hành thực tế, theo Nguyen (2020), các bằng chứng phát sinh từ thông điệp dữ liệu, người cung cấp phải yêu cầu dịch vụ thừa phát lại lập vi bằng. Song nếu áp dụng cách này thì vô hình trung tạo thêm sự gia tăng chi phí, thậm chí giá trị cho việc thực hiện này còn lớn hơn giá trị tranh chấp. Ngoài ra, theo nhận định của Nguyen (2020), khi giải quyết tranh chấp, tòa án có khuynh hướng "nghiêng" về các chứng cứ được cung cấp, xác lập bằng văn bản, nhất là các văn bản đó được công chứng, chứng thực. Mặc dù, các giá trị pháp lý nhất định được pháp luật Viện Nam ghi nhận đối với chứng cứ liên quan đến thông điệp dữ liệu nhưng trong thực tế, khả năng chỉ được xem là chứng cứ bổ sung, hỗ trợ. Một trường hợp tranh chấp thực tế phát sinh từ vụ án kinh doanh thương mại xảy ra giữa nguyên đơn có công ty ở Việt Nam và bị đơn là công ty liên doanh giữa Hàn Quốc và Việt Nam, có trụ sở tại Hà Nội (Le, 2016). Quá trình chào hàng, đưa ra đề nghị giao kết hợp đồng và các thỏa thuận khác đều thông qua phương tiện điện tử như thư điện tử (email), tin nhắn điện thoại, danh sách sao kê các cuộc gọi, sao kê ngân hàng. Tuy nhiên, sau một thời gian giao dịch cung cấp hàng hóa và thanh toán, phía nguyên đơn đề nghị thanh lý hợp đồng và yêu cầu bị đơn thanh toán công nợ. Lúc này phía bị đơn không đồng ý và đưa ra nhiều lý do như: phía bị đơn không nhận được thông tin qua thư điện tử, số điện thoại nguyên đơn liên lạc không phải là số điện thoại của người đại diện pháp luật, các văn bản ủy quyền không hợp lệ, ... Tòa án thụ lý vụ án này đã nhận và kiểm tra tính xác thực từ các chứng cứ bằng thông điệp dữ liệu mà nguyên đơn cung cấp. Tuy nhiên, việc xác thực các chứng cứ này gặp khó khăn do thời gian giao dịch giữa nguyên đơn và bị đơn khá dài, cũng như các máy chủ quản lý dữ liệu không được đặt ở Việt Nam. Kết quả là Tòa án bác bỏ yêu cầu khởi kiện của nguyên đơn. Tuy nhiên, kết quả xét xử của Tòa án đưa ra trong trường hợp này chưa phải là quyết định xác đáng, cần nghiên cứu rõ hơn về hồ sơ vụ kiện và căn cứ vào ý chí thỏa thuận giữa các bên tham gia hợp đồng cũng như hành vi có yếu tố "chấp nhận mà không phản đối" (Điều 142 của BLDS 2015, Quốc hội, 2015a) của phía bị đơn.

\subsubsection{Thiếu quy định cu thể về hình thức chũ ký hình ảnh và chũ kýscan}

Hiện tại pháp luật điều chỉnh về CKĐT bao gồm Luật GDĐT 2005 (Quốc hội, 2005), Nghị định 130/2018/NĐ-CP (Chính phủ, 2018) và Nghị định 52/2013/NĐ-CP (Chính phủ, 2013) chưa quy định cụ thể về chữ ký scan, chữ ký hình ảnh nên hai phương thức ký kết này không được Pháp luật thừa nhận hay không có tính hiệu lực pháp luật.

Tuy nhiên, theo Truong và Huynh (2020), việc công nhận hiệu lực pháp luật của hợp đồng nếu được ký bằng phương thức này nên được nghiên cứu và vẳn bản hóa bởi những ưu điểm mà hai phương thức này mang lại trong giao dịch thương mại điện tử. Ngoài ra, hai tác giả này cũng cho rằng "không có cơ sở pháp lý để kết luận định nghĩa về chữ ký điện tử trong Luật GDĐT 2005 loại trừ chữ ký scan và chữ ký hình ảnh."

Để lập luận về tính pháp lý “khả thi” cho việc sử dụng chữ ký hình ảnh và chữ ký scan này Truong và Huynh (2020) dựa vào hai luận cứ sau: (i) ý chí của các bên giao kết dựa theo quyền đại diện bề ngoài của BLDS 2015 (Khoản 1, Khoản 3, Điều 142, BLDS 2015, Quốc hội, 2015a) và (ii) quan điểm tiếp cận của các thẩm phán Tòa án nhân dân tối cao thông qua các án lệ, bản án (Án lệ số 04/2016/AL ngày 06/04/2016, Chính phủ, 2016b); Án lệ số 07/2016/AL ngày 17/10/2016, Chính phủ, 2016c; Quyết định giám đốc thẩm số 47/2016/KDTM-GĐT ngày 29/08/2016, Chính phủ, 2016d). 

$H Đ Ð T$

4.2.3. Chưa có quy định về công chứng Hợ đồng điện tử Quy định về công chưng

Theo Luật công chứng, công chứng là "việc công chứng viên của một tổ chức hành nghề công chưng chưng nhận tính xác thực, hợp pháp của hợp đồng, giao dịch dân sự khác bằng văn bản (sau đây gọ là hợp đồng, giao dịch), tính chính xác, hợp pháp, không trái đạo đức xã họi của bản dịch giấy tò̀, văn bản tì̀ tiếng Việt sang tiếng nuớc ngoài hoạc tù tiếng nuớc ngoài sang tiếng Việt (sau đây gọi là bản dịch) mà theo quy định của pháp luật phải công chưng hoặc cá nhân, tổ chức tụ nguyện yêu cầu công chưng" (Khoản 1, Điều 2, Luật công chứng số 53/2014/QH13, Quốc hội, 2014).

Như vậy đối với các giao dịch mà pháp luật yêu cầu phải công chứng thì công chứng viên chứng nhận hợp đồng, giao dịch dân sự khác đảm bảo các tính chất pháp luật thì bắt buộc hình thức các hợp đồng, giao dịch dân sự khác đó phải được văn bản hóa.

Theo đó, khi công chứng, Luật công chứng còn yêu cầu bộ hồ sơ như "Phiếu yêu cầu công chúng, trong đó có thông tin về ho tên, địa chỉ người yêu cẩu công chúng, nội dung cần công chứng, danh mụ giấy tờ gửi kèm theo; tên tổ chức hành nghề công chứng, ho tên ngườ tiếp nhận hồ sơ yêu cầu công chứng, thời điểm tiếp nhận hồ so; Dự thảo hợp đồng, giao dịch; Bản sao giấy tờ tùy thân của ngườ yêu cầu công chứng; Bản sao giấy chứng nhận quyền sở hũu, quyền sủ dụng hoặc bản sao giấy tờ thay thế được pháp luật quy định đối với tài sản mà pháp luật quy định phải đăng ký quyền sở hũu, quyền sủ dụng trong truờng hợp hợp đồng, giao dịch liên quan đến tài sản đó; Bản sao giấy tờ khác có liên quan đến hợp đồng, giao dịch mà pháp luật quy định phải có” (Khoản 1, Điều 40, Luật Công chứng 2014, Quốc hội, 2014).

Sau khi kiểm tra, đối chiếu giấy tờ đầy đủ, công chứng viên đồng ý chứng thực thì phải ký từng trang theo quy định của Luật công chứng (Khoản 8, Điều 40, Luật Công chứng 2014, Quốc hội, 2014). Văn bản sau khi được công chứng chỉ có hiệu lực pháp luật "kể tù ngày được công chứng viên ký và đóng dấu của tổ chức hành nghề công chứng" (Khoản 1, Điều 5, Luật Công chứng 2014, Quốc hội, 2014).

Nhìn chung, muốn công chứng hợp đồng, giao dịch dân sự khác thì phải thực hiện trên văn bản giấy. Nếu vận dụng quy định BLDS 2015 quy định "giao dịch dân sự thông qua phuơng tiện diện tư duới hình thức thông diệp dũ liệu theo quy định của pháp luật về giao dịch điện tư được coi là giao dịch bằng văn bản" (Điều 119, BLDS 2015, Quốc hội, 2015a) và các quy định về chữ ký cũng như đóng dấu theo Luật GDĐT 2005 (Điều 12, Điều 24 Luật GDĐT 2005, Quốc hội, 2005; Điều 8 Nghị định số 130/2018/NĐ-CP, Chính phủ, 2018) thì vẫn gặp khó khăn trong việc chứng thực các vấn đề liên quan đến hồ sơ như: văn bản về thừa kế, quyết định ly hôn, giấy đăng ký kết hôn, giấy khai sinh, giấy khai tử, giấy chứng nhận quyền sử dụng đất, quyền sở hữu nhà và các bất động sản khác, hối phiếu, ... do tình trạng hiện hữu của các loại giấy tờ này hiện nay đều được yêu cầu là đối chiếu bản chính, cũng như các cơ quan có thẩm quyền cấp các loại giấy tờ này đều dưới dạng bản giấy. Điều mà Luật Luật GDĐT 2005 không điều chỉnh các đối tượng này (Điều 1, Luật GDĐT 2005, Quốc hội, 2005).

\section{Kết luận và gợi ý}

Xu thế "phẳng" về giao dịch, thương mại giữa các quốc gia trong bối cảnh toàn cầu hóa, tự do hóa thương mại và ứng dụng khoa học kỹ thuật tiên tiến trong kỷ nguyên mới - cuộc CMCN 4.0 đã và đang diễn ra mạnh mẽ. Điều này thúc đẩy các quốc gia điều chỉnh hệ thống quy định Pháp luật của chính mình phù hợp với tình hình chung và thông lệ quốc tế. Do đó đối với một số bất cập về pháp luật giao dịch bằng hợp đồng điện tử tại Việt Nam nêu trên, tác giả đưa ra một số đề xuất mang tính gợi mở, cần nghiên cứu cải thiện như sau:

Thư nhất, đối với tính xác thực của chứng cứ từ thông điệp dữ liệu, cần quy định chi tiết, rõ ràng hơn về "chứng cứ từ thông điệp dữ liệu" nhằm tăng động lực và tạo niềm tin cho các chủ thể tham gia giao kết hợp đồng thông qua thông điệp dữ liệu. 
Thư hai, xem xét sự cần thiết trong việc quy định chi tiết về tính hiệu lực của chữ ký bằng hình ảnh và chữ ký scan. Từ đó tạo cơ sở pháp lý vững chắc trong việc giao kết bằng hai phương thức ký kết này. Đồng thời, nghiên cứu các biện pháp hạn chế, kiểm soát rủi ro về tính giả mạo hay quy định biện pháp xác thực tối thiểu, hiệu quả đối với việc áp dụng chữ ký scan và chữ ký bằng hình ảnh.

Thứ $b a$, đối với việc công chứng HĐĐT, cần rà soát, đánh giá lại các văn bản quy phạm pháp luật hiện đang mâu thuẫn, chồng chéo và lạc hậu điều chỉnh vấn đề này. Song song với việc vừa nghiên cứu, ban hành khung pháp lý điều chỉnh hoạt động công chứng HĐĐT vừa xây dựng, nâng cấp cơ sở hạ tầng công nghệ thông tin và ứng dụng các kỹ thuật tin học để vận hành hiệu quả, kiểm soát được rủi ro, tranh chấp khi triển khai hoạt động công chứng HĐĐT.

Thư tur, khi đã hoàn thiện về hành lang pháp lý, cơ sở hạ tầng công nghệ thông tin trong việc điều chỉnh và vận hành giao dịch bằng HĐĐT, cơ quan quản lý hữu quyền cần tích cực tuyên truyền khuyến khích người dân tham gia giao dịch, ký kết bằng hình thức điện tử để tạo tâm lý an toàn, tin cậy cho các chủ thể tham gia mà còn góp phần tiết kiệm chi phí, đẩy mạnh giao thương, hạn chế các rủi ro và tranh chấp xảy ra khi cần xác thực thông tin. Đặc biệt trong thời điểm dịch bệnh Covid-19 hiện đang là vấn đề gây nhiều cản trở trong giao dịch, thương mại thì vấn đề cải thiện và vận hành giao dịch bằng HĐĐT lại trở nên cấp thiết hơn bao giờ hết.

\section{LỜI CÁM ƠN}

Tác giả chân thành cảm ơn TS. Nguyễn Thị Anh đã dành nhiều tâm huyết giảng dạy và động viên cho các học viên lớp cao học Luật LA1-K30, Khoa Luật, Trường Đại học Kinh tế TP.HCM, trong đó có tác giả. Đây chính là động lực để tác giả đào sâu và nghiên cứu bài viết này. Bài viết là do tác giả tự nghiên cứu, chưa công bố ở bất kỳ hội thảo, tạp chí nào và không có bất kỳ xung đột lợi ích nào liên quan.

\section{Tài liệu tham khảo}

Chính phủ. (2013). Nghị định 52/2013/NĐ-CP quy định về việc phát triển, úng dụng và quản lý hoạt động thuoong mại điện tử, ban hành ngày 16/05/2013, hiệu lục tù 01/07/2013 [Decree 52/2013/NĐ-CP on e-commerce which provides the development, application and management of e-commerce activities, promulgation on 16/05/2013, effect on 01/07/2013]. Retrieved May 10, 2021, from http://congbao.chinhphu.vn/noi-dung-van-ban-so-52-2013nd-cp-4146

Chính phủ. (2016a). Nghị quyết số 04/2016/NQ-HĐTP huớng dẫn việc gưi, nhận đơn khởi kiện, tài liệu, chứng cứ và cấp, tống đạt, thông báo văn bản tố tụng bằng phuơng tiện điện tư giũa nguời khởi kiện, đương sụ, người tham gia tố tụng khác (sau đây gọi là người khởi kiện, ngườ tham gia tố tụng) với Tòa án trong thủ tục giải quyết vụ án dân sụ, vụ án hành chính, ban hành ngày 30/12/2016, hiệu lục tì̀ 15/02/2017 [Resolution 04/2016/NQ-HĐTP which guides the sending and receiving of lawsuit petitions, documents and evidences and the issuance, delivery and notification of procedural documents by electronic means between the plaintiffs, litigants and other procedure participants, promulgation on 30/12/2016, effect on 15/02/2017]. Retrieved May 10, 2021, from https://vbpq.toaan.gov.vn/webcenter/portal/htvb/chitiet?dDocName=TOAAN007673\&Keyword $=$

Chính phủ. (2016b). Án lệ số 04/2016/AL ngày 06/04/2016 [Case law No. 04 /2016/AL on case of "Dispute on the contract on transfer of land use rights", promulgation on 06/04/2016]. 
Retrieved May $\quad$ 10, 2021, from https://anle.toaan.gov.vn/webcenter/portal/anle/chitietanle?dDocName=TAND014300

Chính phủ. (2016c). Án lệ số 07/2016/AL ngày 17/10/2016 [Case law No. 07/2016/AL on recognition of contracts for sale and purchase of house entered into before 1 July 1991, promulgation on 17/10/2016]. Retrieved May 10, 2021, from https://anle.toaan.gov.vn/webcenter/portal/anle/chitietanle?dDocName=TAND014305

Chính phủ. (2016d). Quyết định giám đốc thẩm số 47/2016/KDTM-GĐT ngày 29/08/2016 [Decision of court of cassation No 47/2016/KDTM-GĐT, promulgation on 29/08/2016]. Retrieved May 12, 2021, from https://ketoanmvb.com/ky-ket-hop-dong-bang-chu-ky-sodien-tu.html

Chính phủ. (2018). Nghị định 130/2018/NĐ-CP quy định quy định chi tiết về chũ ký số và chưng thư số; việc quản lý, cung cấp và sư dụng chũ ký số, chứng thư số và dịch vu chứng thưc chĩ ký số, ban hành ngày 27/09/2018, hiệu lục tì 15/11/2018 [Decree 130/2018/ND-CP which provides guidelines for digital signatures and digital certificates, the management, provision, and use of digital signatures, digital certificates and digital signature authentication, promulgation on 27/09/2018, effect on 15/11/2018]. Retrieved May 12, 2021, from http://vanban.chinhphu.vn/portal/page/portal/chinhphu/hethongvanban?class_id=1\&_page $=1 \&$ mode=detail\&document_id=194913

Garner, B. A. (2009). Black's law dictionary. Eagan, MN: West Publishing Company.

Le, T. V. (2016). Chưng cứ điện tủ trong giải quyết tranh chấp kinh doanh thuoong mại [Electronic evidence in resolution of commercial business of dispute]. Tạp chí kiểm soát, (5). Retrieved February 18, 2021, from https://kiemsat.vn/chung-cu-dien-tu-trong-giaiquyet-tranh-chap-kinh-doanh-thuong-mai-46731.html

Martin, E. A. (2002). A dictionary of law (15th ed.). London, UK: Oxford University Press.

Ngo, C. H. (2013). Giáo trình Luật Hợp đồng [Textbook: The law of contract]. Hanoi, Vietnam: NXB Đại Học Quốc gia Hà Nội.

Nguyen, T. T. T. (2020). Hình thức hợp đồng thông điệp dũ liệu và thực tiễn áp dụng [Data message of contract form and practice]. Retrieved February 18, 2021, from Báo điện tử FDVN website: http://fdvn.vn/hinh-thuc-hop-dong-thong-diep-du-lieu-va-thuc-tien-apdung/

O'Sullivan, J., \& Hilliard, J. (2012). The law of contract (5th ed.). London, UK: Oxford University Press.

Quốc hội. (2005). Luật Giao dịch điện tử 2005 số 51/2005/QH11 ban hành ngày 29/11/2005, hiệu lục tù 01/03/2006 [Law No. 51/2005/QH11 on e-transactions which provides for etransactions in the operations of state agencies; in the civil, business, commercial and other sectors prescribed by law, promulgation on 29/11/2005, effect on 01/03/2006]. Retrieved February 19, 2021, from http://vbpl.vn/botuphap/Pages/vbpqentoanvan.aspx? ItemID=6121

Quốc hội. (2014). Luật Công chưng 2014 số 53/2014/QH13 ban hành ngày 20/06/2014, hiệu lục tù 01/01/2015 [Law No. 53/2014/QH13, promulgation on 20/06/2014, effect on 01/01/2015]. Retrieved February 15, 2021, from http://vanban.chinhphu.vn/portal/page/portal/chinhphu/hethongvanban?class_id=1\&_page $=1 \&$ mode $=$ detail $\&$ document_id=175350 
Quốc hội. (2015a). Bộ Luật Dân sự 2015 số 91/2015/QH13 ban hành ngày 24/11/2015, hiệu lục tù 01/01/2017 [The Law No. 91/2015/QH13, promulgation on 24/11/2015, effect on 01/01/2017]. Retrieved February 12, 2021, from http://vanban.chinhphu.vn/portal/page/portal/chinhphu/hethongvanban?class_id=1\&_page $=1 \&$ mode $=$ detail \&document_id=183188

Quốc hội. (2015b). Bộ Luật Tố tụng Dân sụ 2015 số 92/2015/QH13 ban hành ngày 25/11/2015, hiệu lục tù 01/07/2016 [The Law No. 92/2015/QH13, promulgation on 25/11/2015, effect on 01/07/2016]. Retrieved February 10, 2021, from http://congbao.chinhphu.vn/thuoctinh-van-ban-so-92-2015-qh13-18411

Reed, K. M., Cheeseman, H. R., \& Schlageter III, J. J. (2013). Contract law for paralegals: Traditional and e-contracts. Upper Saddle River, NJ: Pearson Education, Inc.

Truong, Q. N., \& Huynh, T. (2020). Ký kết hợp đồng thông qua phương thức điện tử [Signing the contract via electronic means. Tạp chí Nghiên cúu lập pháp, 10(410). Retrieved May 10, 2021, from http://www.lapphap.vn/Pages/TinTuc/210533/Ky-ket-hop-dong-thong-quaphuong-thuc-dien-tu.html

Vu, M. V. (1963). Việt Nam Dân luật luợc khảo - Quyển II: Nghĩa vu và khế uớc [Vietnam Civil Law Summary - Book II: Obligations and Contracts]. Ho Chi Minh City, Vietnam: Bộ Quốc gia Giáo dục. 